\title{
BUSINESS INTELLIGENCE AND IPAD TECHNOLOGY: A MARRIAGE IN THE CLOUD
}

\author{
Joseph Compomizzi, Robert Morris University, compomizzi@rmu.edu \\ Shana M. D'Aurora, Robert Morris University, smdst2@mail.rmu.edu
}

\begin{abstract}
The iPad is a portable computing device. Its most popular features include fast dual core processing, flash storage and touch screen capability. It also can feature a camera and is light weight at approximately 1.5 pounds, and most recent releases of the device have a 10 hour battery. Given this, iPad technology is making an impact on both industry and education.
\end{abstract}

Keywords: Keywords: iPad, Business Intelligence, Dashboard, Hilton International, U.S. Naval War College

\section{INTRODUCTION}

The iPad is a portable computing device. Its most popular features include fast dual core processing, flash storage and touch screen capability. It also can feature a camera and is light weight at approximately 1.5 pounds, and most recent releases of the device have a 10 hour battery. Given this, iPad technology is making an impact on both industry and education. If not embarking more deeply into the mobile computing sector, corporations and academic institutions at least have one eye toward how iPads can benefit them with business decisions, operations, and customer relations, i.e. business intelligence.

According to Michael Vizzard, "B.I. is the only real instance where the existence of the iPad has changed the way people use a particular set of business applications. Apple's tablet makes it easier to flip through reports and gain valuable insights at a glance". According to Soumendra Mohanty, global lead for information management at Accenture, that's helping increase B.I. application usage while altering the way people work: "There's a lot more decision-making taking place outside the office, because people are accessing BI applications on mobile computing devices" (Vizzard, 2012).

In this paper, Business Intelligence (BI) and iPad Technology will be defined in order to promote understanding as to how each component works with the other in providing organizations with alternatives to their everyday decision making and work processes. Business Intelligence and iPads will be examined and their impact on technology operations, as well as, a number of software development applications for use in industry and education. Lastly, in two cases, a review of how Hilton Worldwide is maximizing the use of the iPad for business advantage and how a pilot study done at the U.S. Naval War College demonstrates the contributions the iPad made to the institution academically and financially.

\section{What is Business BI?}

In order to progress in this examination, it is important to have a fundamental understanding of business intelligence (BI). BI may be defined in a number of ways. Dashboard Insight defines it, though, as "turning data into knowledge to support informed decision making. (August 30, 2011). As such, BI requires technology to store data, analyze it, and transform it to information which is usable and presentable to business leaders and customers.

Dashboard Insight (August 30, 2011) assists with understanding these requirements of BI by the use of the following schema. Illustration 1 visualizes what is called the BI Technology Stack. The BI Technology Stack is a composite display of data storage, analysis tools, and output which must work together in order for BI to be realized and beneficial in meeting an organization's strategy needs, support their operations, and meet corporate goals. 


\section{Issues in Information Systems}

Volume 13, Issue 1, pp. 113-120, 2012

\section{Illustration 1: The BI Technology Stack (www.dashboardsight.com)}

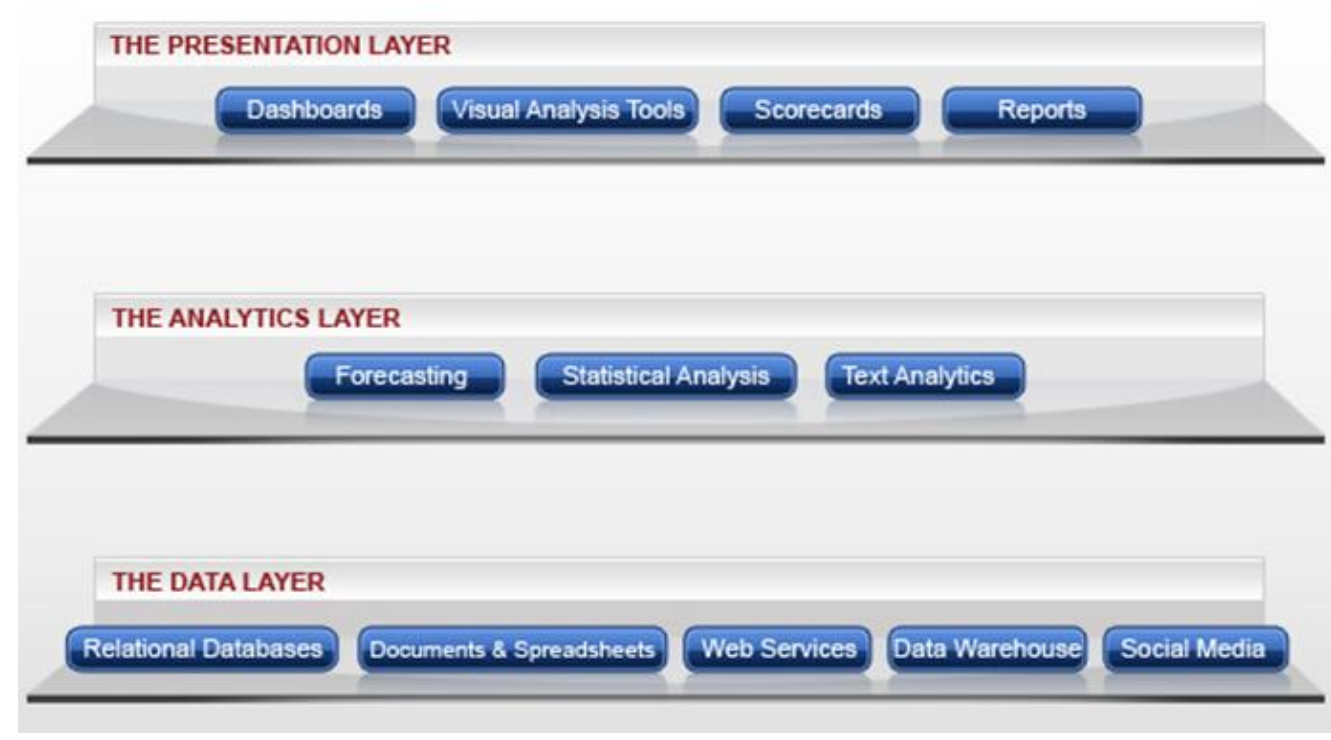

Working from the bottom layer up, data is basically facts, numbers or text in a raw format. In raw format, data is simply material this is waiting to be processed through software programs. Programs, then, are basically directions for data manipulation. In addition, looking at the above illustration, the data layer includes not only data, but also data storage and collection vehicles and communications technologies, like web services, SQL, file servers, Crystal Reports, and spreadsheet and database products which organize data and make it available to an end user.

Next, the Analytics Layer takes the data and packages it at a deeper level for end user use. This is accomplished through software which transforms data into information for a specific business use, for example, sales forecasting, budgeting, and operations volumes/staffing modeling. According to Dashboard Insight (August 30, 2011), this "process of turning data into knowledge is at the heart of BI." Two examples of analytics packages which are included in this layer of the BI Technology Stack include SAP Business Objects and IBM Cognos. For mobile technology, Tibco Spotfire offers real-time intelligence for the financial services industry and SAP Business by Design, Tableau and Jaspersoft BI Suite all offer application packages for other industries. Bitzer Mobile, LeapFactor and Webalo are companies which feature products with the ability to mobilize current enterprise systems for data analysis in a BI environment.

At the highest level in the BI Technology Stack is the Presentation Layer and that which is most visible to end user decision makers. At this layer, processed information from the Analytics Layer is captured and configured for meaningful visualization for management, marketing and information technology end users decision makers. These easy-to-compile and easy-to-manipulate visual displays assist decision makers by presenting data through correlations, trends and patterns, business currents, and business conditions. Detailed graphics, reports, charts, as index cards, photos and other media types, and 3-D imaging offer user interactivity enabling them to drill down and filter specific variables for deeper analysis. Products by Tableau, Inetsoft, Roambi by Mellmo, QlikTech, Yellowfin, and PushBI are but a few which provide presentation of data for effective business intelligence practices.

At the Presentation Layer, there are typically four types of presentation media: dashboards, visual analysis tools, scorecards, and reports all having their unique attributes. First, in an article, Chiang (November 28, 2011) quoting Stephen Few provides a definition of what a dashboard is: "visual display of the most important information needed to achieve one or more objectives; consolidated and arranged on a single screen so the information can be monitored at a glance." Single screen visualization of data analysis and representation is a key feature of dashboards. 


\section{Issues in Information Systems}

Volume 13, Issue 1, pp. 113-120, 2012

According to Chiang (2011), "scrolling to see more violates the definition of a dashboard." Additionally, visualization through dashboard is intended for users at all levels of an organization since presentation of the most important data variables and performance indicators are displayed real-time in user defined and easily understandable formats which are updated automatically without any user intervention. Updates can be preset based on daily, weekly, monthly, quarterly or other defined periods based on organizational need like date ranging analysis.

A visual analysis tool can present visual formatting of data on one screen. However a visual analysis tool also enables users the ability to scroll in the event a table or chart is large or complex for easier viewing. Like the dashboard, it is interactive and allows for drilling down and filtering. Unlike the dashboard, a visual analysis tool is aimed at supporting more technical users. It is especially useful for scatterplot charting and is primarily employed for such tasks as finding correlations between data variables, identifying trends and outliers, and ascertaining key performance indicators for use in dashboards. Further, visual analysis tools are used primarily to present historical data rather than real-time information.

"A scorecard is a tabular visualization of measures and their respective targets with visual indicators to see how each measure is performing against their targets at a glance" (Chiang, November 28, 2011). As its definition states a scorecard basically displays the status of a key performance indicator against its goal. It can contain column and trend displays, as well, and can be employed in a dashboard, but the scorecard is not intended to be interactive. Reports as a visual display typically present numbers and text in tabular format for a user. Reports are aimed at supporting end users who prefer to read text or number data rather than interpret it from a visual representation for off-line manipulation and analysis. A feature of reports, though, is that they are optimized for printing and exporting as a PDF file or into a word processing document.

\section{The iPad}

In a 2010 Microstrategy Inc. survey, $62 \%$ of 2,278 responses cited that "BI is the application companies are most interested in deploying to mobile users (Carr, 2010). While according to this same survey, $72 \%$ of the most widely distributed mobile devices by organizations is Motion's Blackberry smart phone, the number of organizations reporting interest in developing strategies for the device is down $10 \%$ and interest in the iPad is up 15\% (Carr, 2010). One of the main reasons is that the amount of screen real estate is larger than that of the Blackberry and other smart phone devices, but also because of its ability to display, in high resolution and better color, meaningful charts, graphics, reports, and other visuals which better assist with the BI process. It does this by feeds from the backend sources discussed previously in the Data and Analytics Layers section explaining business intelligence.

For the future of business intelligence, iPad technology is viewed as integral. In a BI survey by Dresner Advisory Services, $52 \%$ of respondents who were primarily BI administrators and information technology managers indicated that mobile technology was either critically important or very important with many seeing it "as a must-have capability going forward and a potential game-changer for BI" (Lautzenheiser, 2012). iPad technology is built on Apple's mobile operating iOS system. This platform is built on the concept of human-computer interaction through multi-touch gestures like swiping, pinching, and reverse pinching, touching, and tapping. Through these gestures, users can manipulate objects and presented data for analysis and, consequently, make decisions, communicate them, and publish them from virtually any location. The iPad through human-computer interaction and gesture facilitates interface between the user's need for information with the data stored and processed to the information presented via the three layers of the BI Technology Stack. "The latest Gartner forecast predicts worldwide tablet sales of 19.5 million this year (2010), almost all of them iPads. That will surge to 54.8 million in 2011 and 208 million units in 2014 - that's 10-fold growth in five years" (Robb, 2010).

Gartner also predicts that by 2013, 33\% of business intelligence operations will be spent on mobile devices (readwriteweb.com). Given this, iPad tablet technology is playing a key leadership role in business intelligence initiatives in the for-profit and not-for-profit sectors. With the increased interest in iPad technologies, many enterprise companies are now employing these technologies for their day to day business intelligence operations. 


\section{Issues in Information Systems}

Volume 13, Issue 1, pp. 113-120, 2012

Oracle, reports Conneally (May 3, 2011), performed major updates to its Oracle Business Intelligence (OBI) platform to extend online analytical processing (OLAP) and in-memory platform support with improved real-time decision management capabilities which is available to all iPad users "right out of the box" which means no inhouse customization programming expense and access to alerts; ad hoc and "what-if" analyses; dashboards; reports; and scorecards. Oracle has also improved mobile access so that iPad users can initiate actions and workflows directly from their mobile device to its enterprise system and has expanded its OBI platform so that it can now support data from sources housed in its competition's products like Microsoft SQL Server Analysis Services and SAP's Business Information Warehouse. Like Oracle, Microsoft is expanding its platform to the iPad. Microsoft is now utilizing iPad technologies with their SharePoint software. Employees can now access software such as Microsoft Office: Word, Excel and PowerPoint documents in mobile browsers, which requires that Office Web Apps be installed.

With the SAP BusinessObjects Mobile app for iPad, employees have instant access to targeted, personalized information and are able to make business decisions virtually anywhere there a connection is available. The BusinessObjects app provides instant access to reports, metrics, and real time data which has been optimized for the iPad. With SAP BusinessObjects Mobile, business leaders and information professionals can stay up-to-date and make decisions using the latest information (iTunes.com, 2011).

According to Gunelius (2011), "the iPad makes it easy for enterprise employees and managers to access business intelligence information, manipulate the data, present it to clients, and make decisions on the go." With Goodreader, employees can access and edit PDF files and Microsoft Office documents from enterprise servers. The BoardVantage Collaborate app for iPads enables executives and board members to access information they need for meetings and business strategizing. "Salesforce Chatter has been dubbed the Facebook for enterprises because it helps employees collaborate efficiently and effectively" while WebEX enables them to participate in meetings directly from their iPads (Gunelius, 2011). Another business management app for iPads is called Dropbox. This app enables access to documents from an employee's desktop while they are out of the office and which can be updated from their mobile device. Regarding support for information technology professionals, Wyse PocketCloud is an enterprise app which avails remote access by an employee via their iPad to an enterprise system by connection to the office desktop. MobilIron Sentry is a data security app with enables information technology staff to monitor mobile devices and enforce data policies from an iPad. Consequently, companies have begun to swap or at least supplement employee laptops with iPads as more and more business intelligence apps become available. Apple is not sitting idle with development either. It is actively pushing the iPad to the enterprise market through innovative strategies. The App Store Volume Purchase Program, for example, offers discounts for bulk app purchases of which many companies and colleges are taking advantage.

According to a Gartner report, a new dimension is being added to mobile technologies specifically for BI. The new dimension regards context awareness. To explain, location specific information is of significant importance to businesses and organizations. Having this information accessible through mobile technology like the iPad provides great value for BI operations. Gartner explains that context awareness expands this by providing location based information reporting coupled with additional details about people, for example, customers, colleagues or staff who are in the vicinity. In this way, the BI environment is enriched through information captured by the mobile devices and allocating resources to respond to it (Gartner, 2012). Further, with the capabilities for photo, video and sound capture, mobile technology moves beyond end-point use to a data collection and generation device through context awareness as images are captured and transmitted to company enterprise systems for interpretation, analysis, and execution of appropriate operations initiatives by leaders and workers.

On this note, "while the iPad has already made a significant impact on B.I. in terms of portable data-crunching, MicroStrategy CTO Jeff Bedel suggests the tablet will also affect how workers choose to visualize information. 'Cloud computing is changing the way organizations share information and collaborate" he said (Vizzard, 2012). MicroStrategy is enhancing its' Visual Insight product to enable massive amounts of data to be loaded in-memory with the iPad for more flexible usage by the user. The interesting part to this, though, is that the data comes both from internal sources as well as external data systems, thus allowing organizations to compare proprietary 


\section{Issues in Information Systems}

Volume 13, Issue 1, pp. 113-120, 2012

information to competitive data with a mobile advantage through the iPad with graphics and other features. "The basic idea centers on creating a public or private cloud computing service that allows IT organizations to leverage graphics as a way to more easily consume large quantities of information" (Vizzard, 2012).

In a study by Deloitte, it is forecasted that more mobile devices will be purchased in 2012 than PCs and that Apple's iOS platform will become ever more significant as companies invest in business intelligence (Rosenberg, 2011). BI isn't an organization's only reason for the enlistment of the iPad in their business practices. It comes down to efficiency and productivity in business operations also. IDG Connect (Cave, 2012) reports "companies have stated that the tablet is all work in the office." Managers who expressed concern that employees would use the device for gaming and Facebook found that employees, in fact, use the iPad for business more than $90 \%$ of the time. The report concluded that $97 \%$ of business professionals use the iPad for reading. The iPad's use has also reduced employee's amount of time on their laptops (Sutherland, 2012).

\section{The Use of iPads in Industry and Education: Two Case Examples}

Hilton Worldwide is maximizing mobile technology for both guests and employees. Being one of the first hotel chains to offer free WiFi service, they report use of mobile devices is skyrocketing which is driving technological innovation at the corporation (Kaplan, 2011). Near the top of priorities is heavy investment in business intelligence. Hilton's CIO Robb Webb indicates "We want to really have more time to work on the business, versus assembling and aggregating data" (Kaplan, 2011). To this end, they have formed an internal on-line group commissioned to develop a mobile strategy. Hilton has coupled this move with the implementation of the Hilton Innovation Collaborative which is what they call their partnering initiative with best in class technology companies to address information technology needs from all angles including reservations, e-mail communications, and property management systems, back office operations, quality assurance, business intelligence, financial systems, productivity tools, WiFi and internet servicing. The concept is unique according to Webb: "if you go across the major hotel companies, there's a high level of fragmentation. Most hotels are dealing with a great deal of legacy complexity” (Kaplan, 2011).

Capitalizing on the context awareness capability, the partnership has introduced applications for guests including a virtual concierge enabling guests to order room service and access other information about services offered by the location specific hotel through rich audio and video links to the property management system. Guests can also access location-based services available near the hotel through another app connecting them with places of interest, shopping, dining and a whole host services to meet their needs while staying at a Hilton property.

In the back office, other uses employed through the iPad at Hilton are participation in online forums and sharing best practices among management and leaders especially with technology information. Most important from the technological standpoint, though, is the availability of analytics used to offer right pricing and maximize yields on rooms. According to Webb, "Hilton Worldwide is a very fortunate company in that we have invested in technology. Tech innovation is not new to us. We have a single image of our inventory globally, unlike several of our competitors, and this has been a huge advantage for us. We can take a snapshot of what rooms are filled tonight globally" (Kaplan, 2011).

Educational institutions are also getting in the mix when it comes to teaming up with iPad technologies. The Net Generation, whose members were born in and after 1982, is the largest generation in U.S. history, surpassing 80 million in number (Junco and Mastrodicasa, 2007). The merging of mobile technologies into student-centered learning environments entails academic institutions to scheme more effective learning, teaching, and user experience strategies. Several universities are issuing iPads to students and studying their academic and social effect. The Reed College iPad Study by Marmarelli and Ringle identifies several benefits of iPads supporting the student learning experience (p. 3-4). Other universities like Notre Dame and Seton Hill are reporting benefits to time management, improved peer student collaboration and communication, improved student-professor communications and relationships, and research benefits. 


\section{Issues in Information Systems}

Volume 13, Issue 1, pp. 113-120, 2012

Roberts (2010) indicates that the U.S. Naval War College has begun research on iPad's with 126 of its 3,850 students and 34 faculty members. Applications were pre-loaded before distribution to the sample population. The study focuses on student habits, perceptions, and preferences in regard to iPad use. As Table 1 presents, regarding student responses on study habits and functions, a majority of the participants indicated either that they "frequently" or "always" use the iPad for web browsing, application use, accessing news, and for e-mail.

Table 1: Student Habits with iPads/U.S. Naval War College Source: Roberts (2010)

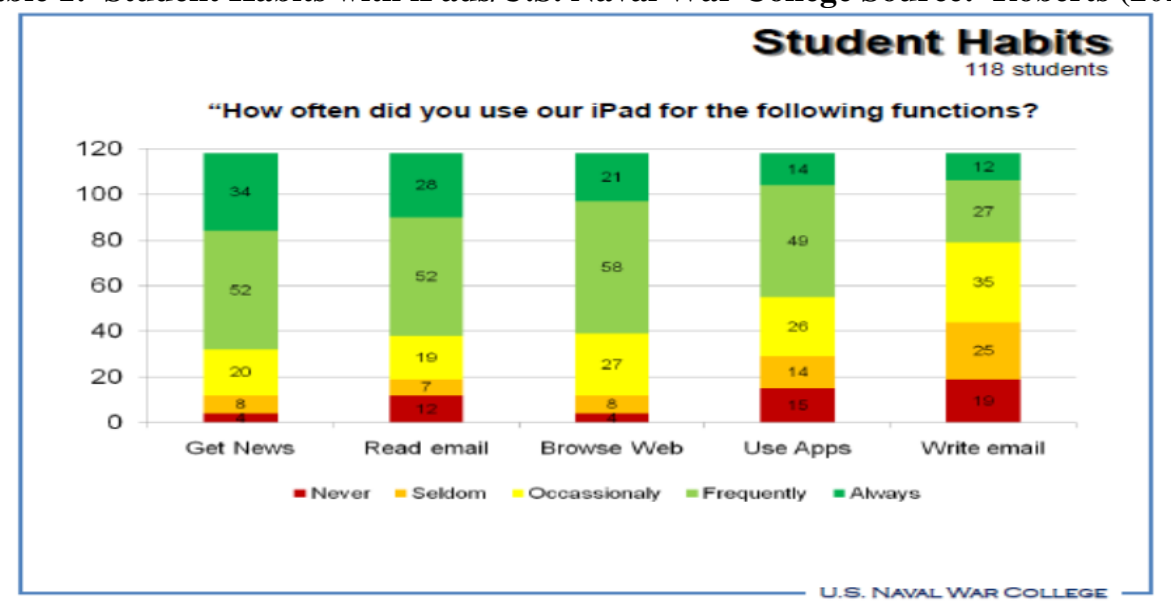

When questioned about the uses and benefits of the iPad, the primary feedback given by students includes ease of use, reading, annotating, class preparation, and comprehension benefits. While writing papers was also identified as a benefit, most indicated they would still use a laptop or desktop for this function. Overall, eighty-two percent of the sample student population indicated that they would like materials for future courses accessible by iPad technology. As with other studies, professors at the U.S. Naval War College indicated increased dynamics in their classes with the iPads with fifty-five percent indicating improved quality of classes (Roberts, p. 23). A majority also noted the benefits of having all their reading materials in one place with them at all times and that the iPad was a useful tool in the classroom.

The U.S. Naval War College participates in The App Store Volume Purchase Program with Apple. Another major aspect of the iPad study was to determine if paper and print costs could be reduced by enlistment of the device. On the average, 8,300 pages of printed materials and 58 books are issued to each student for a program of study. Instead of providing hardcopy of the printed materials, professors made them available electronically through Blackboard as PDF files maintained on the institution's file servers. These files were then converted through the iAnotate app by each student who could use them, mark them, and highlight the texts as needed. The paper and print savings to the College was significant. Likewise, books did not have to be purchased in hardcopy, but were made available to students and faculty through the Goodreader app.

\section{CONCLUSIONS}

Mobile technology is gaining ground far beyond simple social networking and communications uses. As discussed forecasts show, the iPad is becoming a mainstay when it comes to business intelligence. This mobile device offers ease of use to decision makers by linking them to the BI Technology Stack which makes rich presentation and manipulation of data available quickly. To keep up, software platform vendors like Oracle are making interfaces to data sources easier with aggressive product enhancements making BI more available and flexible to organizations in both the for-profit and non-profit sectors with noteworthy financial, technological, and operational results. As both continue to develop, the effects of the marriage of BI and the iPad promise a bright future in supporting the needs of organizations. The above mentioned research was concluded to contribute to the empirical research already established with iPad technology and business intelligence. Further research can be conducted to investigate iPad 


\section{Issues in Information Systems}

Volume 13, Issue 1, pp. 113-120, 2012

technology and its relationship to cloud computing and distance education. For the purpose of this research only business intelligence was researched.

\section{REFERENCES}

1. Carr, D.F. (December 23, 2010). Business intelligence goes mobile on the iPad and iPhone. Forbes. Retrieved http://www.forbes.com/sites/davidcarr/2010/12/23/business-intelligence-goes-mobile-on-ipad-and-iphone/.

2. Cave, K. (January 16, 2012). IDG Connect Report Shows $91 \%$ of Worldwide IT and Business Professionals Use Their iPad for Work Communication. Retrieved from http://www.marketwatch.com/story/idg-connectreport-shows-91-of-worldwide-it-and business-professionals-use-their-ipad-for-work-communication-2012-0116

3. Chiang, A. (November 28, 2011). What is a dashboard? Defining dashboards, visual analysis tools and other data presentation media. Retrieved from http://www.dashboardinsight.com/articles/digitaldashboards/fundamentals/what-is-a-dashboard-aspx.

Kaplan, M. D.G. (January 26, 2011). Hilton CIO mobile device use in hotels is skyrocketing. Smartplanet. Retrieved from http://www.smartplanet.com/blog/pure-genius/hilton-cio-mobile-device-use-in-hotels-isskyrocketing/5332

Lautzenheiser, D. (December 1, 2010). Mobile BI: how to run your business on the iPad. Retrieved from http://www.enterprisemobiletoday.com.

4. Marmarelli, T. and Ringle, M. (2011). The reed college ipad study. The reed institute. Retrieved from http://134.10.15.75/cis/about/ipad_pilot/Reed_ipad_report.pdf.

5. Rice, A. (October 18, 2011). Colleges Take Varied Approaches to iPad Experiments, With Mixed Results. Retrieved from http://chronicle.com/blogs/wiredcampus/colleges-takevaried-approaches-to-ipad-experimentswith-mixed-results/3374

6. Conneally, T. (May 3, 2011). Oracle updates business intelligence with iPad in mind. Retrieved from http://betanews.com/2011/05/03/oracle-updates-business-intelligence-with-ipad-in mind/.

7. Dashboard Insight (August 30, 2011) What is BI? a primer on business intelligence. Retrieved from http://www.dashboardinsight.com/articles/digital-dashboards/fundamentals/what-is-bi-aspx.

8. Finley, K. (February 9, 2011). 10 Business Intelligence Tools for the iPad. Retrieved from http://www.readwriteweb.com/enterprise/2011/02/10-ipad-business-intelligenceltools.php

9. Gallen, C. (January 4, 2011). Three billion downloads in just one year, still outgunning android tablets. ABI Research. Retrieved from http://www.businesswire.com/news/home/20120104006074/en/iPad-Hits-BillionDownloads-Year-Outgunning-Android.

10. Gunelis, S. (December 30, 2011). 12 killer apps for enterprise business management. Retrieved from http://sproutsocial.com/insights/2011/12/ipad-apps-enterprise-business/.

11. iTunes.Apple (2011) SAP Business Objects Mobile. Retrieved from http://itunes.apple.com/us/app/sapbusinessobjects-mobile/id441208302?mt=8

12. Junco, R. \& Mastrodicas, J. (2007). Connecting to the Net.Generation: What higher education professionals need to know about today's students. Retrieved from http://www.mendeley.com/research/connecting-tothe-netgeneration-what-higher education-professionals-need-to-know-about-todays-students/

13. Roberts, J. (August 4, 2011). The NWC iPad pilot. U.S. Naval War College. Retrieved from http://www.adlnet.gov/wpcontent/uploads/2011/08/roberts_iPad_pilot_naval_war_college_iFest2011.pdf.

14. Robb, D. (November 22, 2010). Is Apple's iPad changing CRM and business intelligence? Enterprise Apps Today. Retrieved from http://www.enterpriseappstoday.com/business-intelligence/is-apples-ipad-changingcrm-and-business-intelligence-1.html

15. Rosenberg, D. (September 27, 2011). Business Intelligence heads to the iPad. Retrieved from http://news.cnet.com/8301-13846_3-20111970-62/business-intelligence-heads-to-the ipad/

16. Sechrist, S. (January 19, 2012). SharePoint Upgrade Supports iPad Mobile Business Intelligence Sort of. Retrieved from http://www.cmswire.com/cms/informationmanagement/sharepoint-upgrade-supports-ipadmobile-business-intelligence-sort-of 014171.php 


\section{Issues in Information Systems}

Volume 13, Issue 1, pp. 113-120, 2012

17. Sutherland, E. (January 17, 2012). More And More Businessmen Are Chucking Their Laptops In The Trash For iPad. Retrieved from http://www.cultofmac.com/140925/more-and more-businessmen-are-chucking-theirlaptops-in-the-trash-for-ipad/

18. Vizzard, Michael (May 7, 2012). Apple iPad Is Evolving the Business Intelligence Market. Retrieved from http://slashdot.org/topic/bi/apple-ipad-is-evolving-the-business-intelligence-market/

19. Bitterer \& Sood (April 24, 2012). Mobile Business Intelligence Puts Data on the Road. Retrieved from http://www.forbes.com/sites/gartnergroup/2012/04/24/mobile-business-intelligence-puts-data-on-the-road/ 